\title{
Picturing Atrocity: Photography in Crisis
}

edited by Geoffrey Batchen, Mick Gidley, Nancy K. Miller, and Jay Prosser

London: Reaction Books, 2012, 320 pages

ISBN: 9781861898722 (paperback) Price $£ 20$

Reviewed by Sally Miller, University of Brighton

This is a timely, if not overdue, collection of interesting and thought-provoking essays on the relationship between photography and atrocity. The scope of the book is impressive, featuring journalists, historians, theorists and artists, and discussing a range of photographs from the infamous to neglected and newly discovered images. However, it disappointingly fails to amount to the sum of its parts. Individually, the essays are engaging and often provocative, beginning with Rebecca Solnit's brief, passionate reminder of the importance of context and the responsibilities of the media regarding the aftermath of the Haitian earthquake. This is followed by contributions from a range of theorists including Peggy Phelan, Griselda Pollock and David Campbell who add academic weight before the collection concludes with artistic works by Alfredo Jaar (in collaboration with David Levi Strauss) and Lorie Novak. It is an undeniably varied collection that covers lot of ground, however, its diversity is not always productive. For example, photography is used very broadly to talk about images that are produced by various means and that go on to appear in a range of contexts. This means that photography and in particular, the photograph, is strangely elsewhere. Indeed, it is disappointing that, in a collection that identifies photography as its key area of concern, there is so little discussion of photography. The root of the problem perhaps lies in the fact that, although the book carries the subtitle 'Photography in Crisis', the contributions do not share an interest in photography or a photography theory - rather they are united by humanitarian concerns. This is fitting for a collection that began life as a conference staged in memory of Susan Sontag and in support of Amnesty International (royalties from the book will also be donated to Amnesty International). However, the political kinship of the contributions means that, despite the 
range of approaches and examples utilised, the collection sadly fails to ignite dialogue, and this is ultimately a useful, but not very dynamic collection.

Of greater is concern is the fact that, while its humanitarian impetus produces some compelling writing, the charged rhetoric also gives rise to theoretical laxity in places. For example, the photograph is repeatedly described as a 'witness'. The attribution of agency to the photograph is problematic; photographs do not 'speak' to us. This not to claim that photographs are not affective, but the address of the photograph is not direct nor is it singular, and it is important to remember that a humanitarian response to images of atrocity is but one of the reactions that can take place. The ongoing circulation of the Abu Ghraib images on the internet on and the emergence of the 'torture porn' film genre suggest that pleasure is also a popular, though not politically desirable, reaction to these images. Indeed, atrocity has long functioned as an as object of enjoyment in cinema, literature and art. Further, an identification with atrocity can produce 'enjoyment'. An extreme manifestation of this can be seen in cases where individuals have falsely claimed to have been victims of atrocity. Binjamin Wilkomirski's false autobiography Fragments (1997) is a well-documented example from the Holocaust. A more recent example would be the case of Alicia Esteve Head who falsely claimed to be a survivor of the terrorist attacks on the World Trade Centre. That is to say, it is important to recognise that it is not only the perpetrator (or those aligned with the political views of the perpetrator) who might find a form of pleasure in viewing atrocity photographs. Contributions attentive to the less desirable identifications that can sometimes arise when viewing images of atrocity might have been productive in offering a greater sense of 'photography in crisis'.

There are two contributions that are notable for the modest but effective interventions they pose. Rather than seeking the empathetic identification with the victim that is the mainstay of many academic responses derived from trauma theory, these works are concerned with transforming the mode of our engagement with images of atrocity. The first is Solnit's proffering of alternative 
captions for images from the aftermath of the Haitian earthquake. These seek to effect a change in public perception of an event whose history is still being written. Dovetailing with Solnit's as the penultimate contribution is Alfredo Jaar's collaboration with David Levi Strauss, 'Lament of the Images'. Consisting of descriptive captions for well-known images from a range of conflicts underneath blacked-out images, Jaar and Strauss' piece also directs us to an awareness of the role that the media plays in framing events. Deceptive in its simplicity, the work solicits a potent consideration of context and the affective work of photographs Prompted to visualise these notorious photographs, a range of memories and identifications come into play. The work thus foregrounds the multifarious nature of the photographic image and its dynamic resistance to a singular reading - no matter now politcally desirable that reading is . This is something that we must embrace if the crisis in photography theory is to be resolved. 